\title{
Н.К. Данилова
}

\section{САКРАЛЬНОЕ ПРОСТРАНСТВО: АРХИТЕКТУРНОЕ ВОПЛОЩЕНИЕ ТРАДИЦИОННОГО МИРОВОЗЗРЕНИЯ НАРОДА САХА}

\author{
Исследование выполнено в ралках гранта Российского научного фонда (проект №14-38-00031)
} и РГНФ-ФДНЧ (проект № 15-22-08501).

\begin{abstract}
Рассматривается Могол ураса - монументальное стационарное сооружение народа саха, покрытое берестяными полотнами В жилищно-поселенческом комплексе Могол ураса представляла собой летний вид жилища. Выступала мерилом знатности и богатства человека. В семантическом контексте Могол ураса была связана с моделью мироздания, с культовой архитектурой, сохранившей осознанную идейную программу символического моделирования Вселенной. Анализ фольклорноэтнографических материалов показал, что берестяная ураса как жилище - хранительница человеческой жизни - была связана с культом богини-матери (культом Земли) и культом предков. В культурном наследии народа саха является ключевым символом сакрального пространства.

Ключевые слова: Могол ураса; семантика и образ; миф и ритуал; культурная традиция; сакральное пространство.
\end{abstract}

Народ саха является самым северным тюркоязычным народом Сибири, в этногенезе которых приняли участие различные тюрко-монгольские и автохтонные племена. Уникальность этого народа заключается в том, что они представляют в пространстве арктической цивилизации островок южной культуры тюркоязычных предков. Одним из ключевых символов якутской культуры и верхом архитектурного вкуса, вобравшим в себя все богатство народных знаний и представлений, является монументальное стационарное сооружение из берестяных полотнищ - Юс курдуулаах Могол ураса (с тремя опоясками Могол ураса). Так, якутский народ в результате сложного этно- и культурогенеза, сохранив южные элементы, создал в условиях Крайнего Севера уникальную архитектурную культуру.

В конструкции Могол урасы все соответствовало вертикальным и горизонтальным направлениям мира. Как подметил известный якутский этнограф А.И. Гоголев, «...дом человека - модель микрокосмоса. Это хорошо иллюстрируется на примере архитектоники Могол урасы, летнего жилища якутов, центром которого является очаг, маленький земной образ солнца» [1. С. 25].

Могол ураса - коническое стационарное сооружение, покрытое берестяными полотнищами, представляет собой летний тип жилища. Отличалась от остальных типов якутских жилищ своей монументальной конструкцией. Так, Могол ураса состояла из трех частей, поэтому в мифопоэтике про нее говорится Юс курдуулаах Могол ураһа (с тремя опоясками Могол ураса). Высота достигала 10-12 м, одновременно внутри урасы могли находиться до 100 человек (рис. 1).

Первая, нижняя часть урасы состояла из вкопанных в землю столбов (обычно двенадцати, обозначающих годовой цикл) высотой от 2-2,5 м каждый. Каждый из столбов имел наверху полукруглую вырезку, на которую накладывали круг из двух или трех согнутых жердей. Круг этот назывался маннайгы курдуу (первая опояска). После этого устанавливали конический остов, для чего вначале ставили три длинные жерди, которые связывались между собой у верхушки конуса. Вокруг этих основных жердей устанавливались остальные, верхушки которых привязывались к верхнему обручу (к третьей опояске. - Н.Д.) длинной веревкой «иирчигэн быа». Эта веревка из конского волоса, оканчивающаяся кистями, ниспадала по обеим сторонам двери [2. С. 98].

Поверх шестов накладывался внешний покров из берестяных полос, называемых macna. Похожий термин существует у тюрко-монгольских народов: тюркское тасма, macna обозначает полоску из кожи, монгольское тасама - ремень из кожи оленя [3. С. 124].

На остов урасы сначала прикрепляли нижний слой бересты. Края верхних слоев заходили на края нижних подобно черепице, поэтому осадки не проникали внутрь. Бересту внутреннего покроя окрашивали в красновато-коричневый цвет отваром ольховой коры. Кроме того, на бересту наносили орнамент путем прорезов на белой кожице бересты, коричневых слоев, или покрывали аппликациями из продымленной или окрашенной в черный цвет березовым наростом бересты, образующей геометрические фигуры. Иногда под узорные вырезы подкладывали пластинки слюды.

Покрыв остов одним слоем бересты, накладывали второй - наружный. Он подвязывался по второму наружному ряду жердей, устанавливавшихся по отношению к внутренним, в шахматном порядке, но не сразу, а по одному, по мере подвязывания бересты. Для удобства установки жердей наружные полосы покрышки подвязывались вертикально снизу вверх с помощью длинной лестницы.

После покрытия остова двумя слоями бересты на расстоянии одного или двух метров от верхнего края покрышек привязывают волосяной веревкой деревянный круг, подобный внутренним опояскам, называвшийся «тас курдуу»- внешняя опояска (вторая по счету, средняя опояска. - Н.Д.). Жерди, скрещенные на верхушке урасы, связывались толстым тальником в виде обруча. Вязка эта называлась кепсе [4. С. 24-32]. 


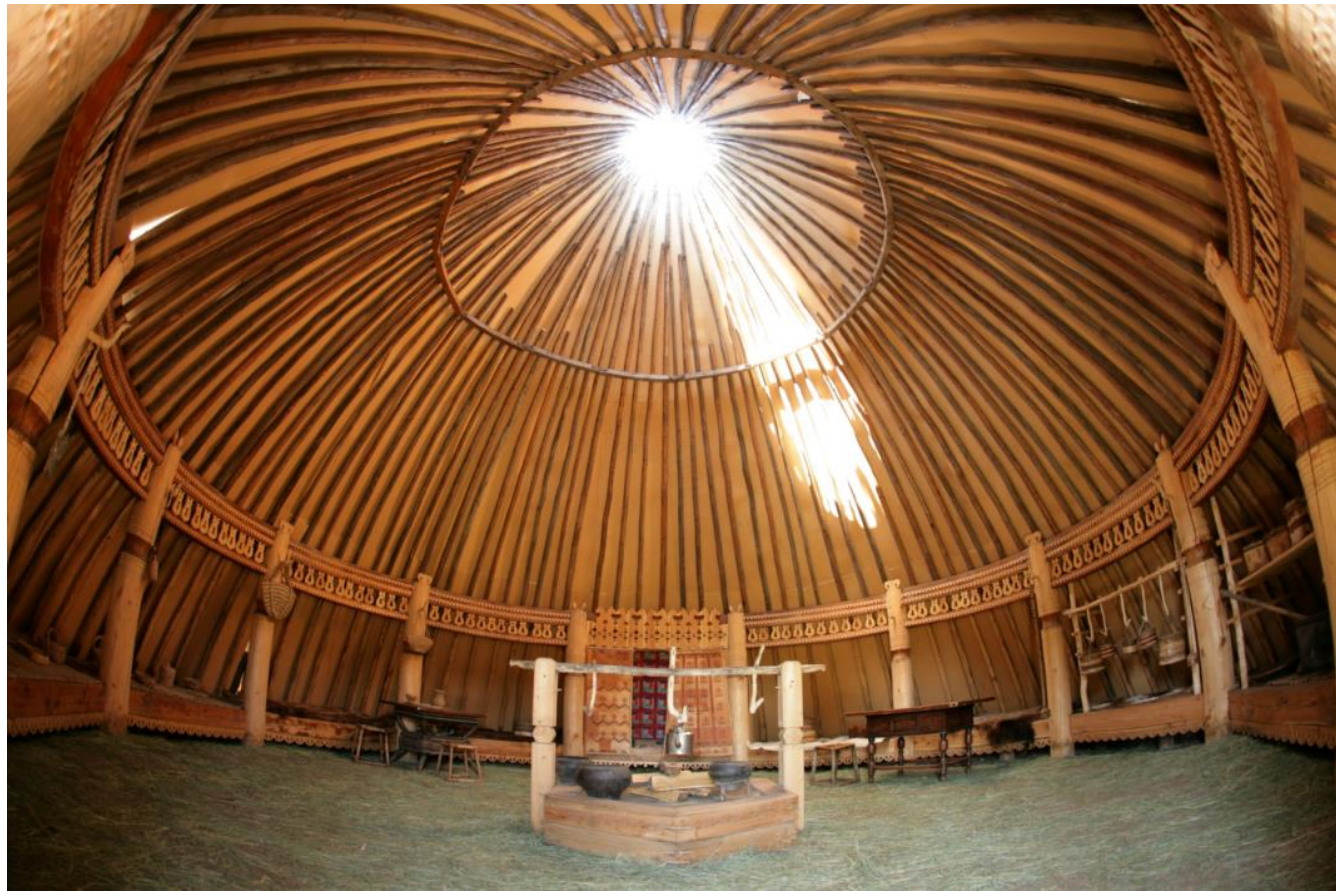

Рис. 1. Внутреннее пространство Могол урасы (реконструкция). Из фотоархива Института гуманитарных исследований и проблем малочисленных народов Севера СО РАН

В самом верху конуса оставляли отверстие, через которое проникал свет, а дым очага уходил наружу. Отверстие это называлось ураа (бур. урху, урхэ; монг. opyxe) [5. С. 145].

Все действия по установке урасы совершались согласно движению по солнечному кругу. Деревянный остов Могол урасы устанавливали мужчины, а берестяные полосы изготавливались и украшались исключительно женщинами [6. С. 12].

Поразившим своим великолепием приезжих людей был конечно же внутренний интерьер урасы. В центре располагался квадратной формы очаг холумтан, который поддерживался двумя или четырьмя опорными столбами с резным верхом (в форме коновязи сэргэ. - Н.Д.).

Начиная от входа вокруг стены урасы располагались лежанки для сидения и спанья - ороны (бур., алт., телеут. орон - кровать, место сна). Обычно их было 12, но в преданиях рассказывается об урасах именитых богачей, в которых ороны доходили до 25 [Там же. С. 14].

Одним из самых примечательных и нарядных частей урасы выступала берестяная занавеска хапnахчы (комнатки) девушки.

Xannaxчbl (от слова xannax - крышка, покров; тюрк. капак, кабаз - крышка, кампак - две половинки ворот или дверей) богато орнаментировалась вышивкой и серебряными (медными) подвесками с нанизанными в них стеклянными бусами и колокольчиками.

Одним их характерных особенностей внутреннего интерьера урасы является художественное оформление внутренних столбов. Столбы внутри урасы и лежащий на них обруч покрывались резным орнаментом, нанесенным якутским ножом. Это был шахматный или растительный узор. Ф.П. Врангель писал: «Необычно большие размеры ypacbl, орнаментика на столбах и берестяных xannaxчbl, нарядная конская упряжь, вооружение и одежда, развешанные на вешалках, производили весьма приятное впечатление. В этих урасах свет легок для глаз, всегда прохладно и комаров не бывает» [7. С. 239].

Могол ураса выступала мерилом знатности, богатства человека. Наличие такого вида жилища свидетельствовало о высоком социальном статусе человека, поэтому ее могли позволить себе только родоначальники и именитые люди.

В старину урасы ставили в целом ансамблевом комплекте. Могол ураса родоначальника стояла в центре круга, вокруг которого были расположены урасы меньших размеров, которые назывались Далла ураса и Ходьол ураса. Расположение урас напоминало куренное построение кочевий монголов в XI-XIII вв. Куренем они называли поселение, состоявшее из кибиток, поставленных по кругу. Рашид ад-Дин писал, что монгольский курень состоял из большого числа кибиток, расположенных по кругу, в центре которого размещалась кибитка старейшины рода. В работе С.Г. Жамбаловой приводятся сведения, что курень был подобен планировке святилища, посвященного богу неба Тэнгри-хану, и способствовал созданию авторитета центральной власти князя-хана, исполнявшего функции администратора и жреца [8. С. 113].

Исследователи по-разному объясняли происхождение этого типа жилища. Некоторые считали, что отсутствие жилищ с конструкцией, как у Могол урасы, у тюркомонгольских народов свидетельствует о том, что она возникла в результате оседлого хозяйствования взамен легких переносных конусообразных жилищ, 
перенятых у автохтонных народов (тунгусов). Другие утверждали, что Могол ураса имела свои прототипы на юге, затем по мере приспособления к новым климатическим условиям на Севере произошли изменения, отчасти усложнение и усовершенствование ее структуры.

Впервые о южном происхождении Могол урасы высказал предположение А.А. Попов, идею которого развили в своих исследованиях О.В. Ионова и Ф.М. Зыков. Определенный интерес вызывает и значение слова могол. А.А. Попов слово могол определял как «большая, солидная». О.В. Ионова переводит как «монгольский» или как «большой, великий, священный, важный». «Употребление этого названия в настоящее время для урасы постоянного типа, как нам кажется, подсказано фольклорной традицией», - отмечал Ф.М. Зыков [9. С. 58].

Интересна интерпретация слова могол Г.В. Ксенофонтовым: «В старинных преданиях встречается имя “Тюёнэ Могол” как одного из предков якутов. Далее, в шаманских песнопениях “могол” выступает как общее название душ предков, перевоплощающихся в перелетных птиц. Тем же словом в вилюйском регионе отмечается особая масть конного скота, посвящаемого духам. Во всяком случае, близкая связь этого термина с культом предков не подлежит сомнению. С другой стороны, якутское “монгуол-могол” несомненно, имеет какое-то близкое отношение к племенному названию “монгуол - могол”, как известно, взятому из древних преданий дочингисовой Монголии. По совокупности приведенных данных, мы лично приходим к выводу, что название «Могол ураса» имеет смысл - ураса душ предков, храм предков или священная ураса» [10. С. 22].

Кроме того, в фольклорных и архивных источниках встречаются сообщения о божествах - покровителях домашнего скота Могол Тойон (Большой Господин) с женой Уһун Куйаар Хотун (Высокая Космическая госпожа); Тюенэ Могол - покровитель конного скота и его жена Тюптэ тэллэх, Тёгюрук оноо, уһун Могол Хотун (с постелью из кострища, в шубе с круглым орнаментом, высокая Госпожа Могол). Эпитет Могол Тойон фигурирует также и как один из имен в названии духа хозяина очага: Бырдьа бытык, кемер сыттык, Могол тойон, Аан Дьааһьн (Белеющая борода, пепельная постель, Господин Могол, Аан Дьааһьлн) [Там же. С. 120].

Появление просторной берестяной Могол урасы приписывается Эллэй Боотуру - культурному первопредку якутов [11. С. 38]. Он же является первым айыы-шаманом, устроителем ритуального празднества Ысыах.

Первоначально Эллэй воздвиг берестяную Могол урасу для совершения молебна в честь небесных божеств Айах mутуy (Обряд держания кумысной чаши или восхваление небесных божеств). Таким образом, во время праздника Ысыах Могол ураса служила своего рода храмом [10. С. 6]. Обряд Айах тутуу совершался внутри просторной берестяной урасы (позднее данный обряд стали проводить внутри балагана, а функцию айыы-шамана стал выполнять почетный старец, знаю- щий слова молитвы). Следует отметить, что подобные ритуалы под названием «жертвоприношение небу» или «моление горам» в прошлом зафиксированы у всех тюркоязычных групп населения Южной Сибири [12. С. 25].

В обряде участвовали только старейшины ага yyha и именитые богачи. В гости приглашались именитые и родовитые люди, а простой народ, женщины и дети к обряду не допускались. Расположение людей внутри урасы во время проведения ритуала было строго регламентированным. Почетное место, которое занимал сам устроитель Бlcblaxa, находилось напротив раскрытых дверей, обращенных на восход солнца. Во время совершения обряда никто не имел права проходить мимо дверей урасы, так как, по мифологическим представлениям саха, с восточной стороны спускается на землю тропа/дорога сиэл намылга аартык - дорога небесных божеств [10. С. 10].

При айыы-шамане находился жрец-помощник, обязанность которого сводилась к разбрызгиванию кумыса особой священной ложкой эбир хамыйах духам предков. Жертвоприношение кумыса главным божествам состояло в том, что чашу с кумысом держали на вытянутых руках и при этом призывали божества по их именам, называя их в порядке значимости. Предполагалось, что небесные божества должны были незримо прикоснуться к священному напитку. После свершения обряда гадали, обращаясь к предкам с мольбой оказать содействие [13. С. 116-117].

В данном ритуале, так же как и в других, направленных на моделирование космического миропорядка, акцентируется восточное направление. Так, восток (весна и утро), как место восхода солнца, становится точкой отсчета «воссоздания» Мира, откуда началось развертывание пространственно-временного континуума.

Далее, постепенно продвигаясь по направлению солнца, айыы-шаман возносил моление небесным божествам - покровителям рода и домашнего очага. Айыышаман по ходу солнца поочередно обращался ко всем сторонам света и находившимся там светлым божествам-айыы. Затем, вознося чашу с кумысом, прикреплял березовую веточку к главным столбам Могол урасы [10. С. 13]. Таким образом, айыы-шаман замыкал круг пространственно-временного континуума. После этого начиналось распитие освященного кумыса (наполненною сакральной силой небесных божеств. - Н.Д.) сначала присутствовавшими там людьми, затем чорон с кумысом передавали находившимся снаружи людям.

Предназначение Могол урасы как культового храма прослеживается и в его конструкционном облике. Вертикальная структура и его трехчастное деление (юс куурдуулаах Могол ураһа), устремленность ввысь, внутренняя колоннада из 12 столбов, означающих 12 небесных сфер, круглое основание воспроизводят устройство Вселенной, космического и социального порядка. Об устойчивом и длительном использовании берестяной урасы как основной формы жилища самих якутов и их предков свидетельствует то, что Вселен- 
ную якуты представляли в виде ypacbl: «Небесный купол - ее вершина, края ее сходятся с землей» [14. C. 35].

Ураса как модель Вселенной встречается также и в символических текстах старинных загадок и поговорок, а космогоническая символика прослеживается и в художественном оформлении берестяных покрышек, и резных столбов урасы. Так, ураса украшалась слоями орнаментов, среди которых преобладал арочный орнамент. Подобный орнамент встречается и в оформлении ритуальной кумысной утвари.

Трехчастная структура модели мира запечатлена в структурной композиции Могол урасы. Как и Вселенная, Могол ураса состоит из трех частей: нижнего, среднего и верхнего (наличие трех опоясок).

С образом Нижнего мира (Земли) связана нижняя часть урасы, берестяное покрытие которой разукрашена растительным узором. Круглое основание символизирует круг - лоно Земли, а орнамент - его оформление. Кроме того, растительный орнамент обладает охранными функциями (препятствует вторжению с Нижнего мира темных сил абаahbl).

Означающая Средний мир внутренняя опояска богато разукрашена резным орнаментом и «культурно обработанным» вещным оформлением - саламой (веревкой из конских волос с нанизанными в ней лоскутками, миниатюрными берестяными туесками и телячьими нарыльниками).

Верхняя опояска юёһээни курдуу (верх, Верхний мир) олицетворяет символ Неба, так как в ней находится светодымовое отверстие ураа. Являясь единственным источником света в урасе, ураа обладает высокосемиотичным статусом, так как представляет собой пограничный элемент между жизненным пространством человека и миром природы. Определение светодымового отверстия как своеобразной «двери» в запредельные миры - понятие универсальное.

Таким образом, Могол ураса в семантическом контексте была связана с моделью мироздания, с культовой архитектурой, сохранившей осознанную идейную программу символического моделирования Вселенной.

Рассматривая сложную семантическую нагруженность Могол урасы, следует отметить, что берестяная ураса как жилище - хранительница человеческой жизни - была связана с культом богини-матери (культом Земли) и культом предков. Так, анализируя вещное оформление якутских ысыахов, Е.Н. ДьяконоваРоманова выявила тесную смысловую связь Могол ураcbl с резными столбами аар багах (ритуальные столбы, в которых во время праздника Ысыах подвешивали кожаный сосуд с кумысом. - Н.Д.). Ритуальные столбы aар багах были окружены молодыми березками, верхушки которых связывали вместе [15. С. 50]. В результате получалось сооружение, конструкция которого напоминала схематический образ урасы.

У якутов свежесрубленные молодые березки, используемые в ритуалах, называются чэчир (древне- тюркск. йашт; татар. йэшир; алтайск. йажар; чуваш. ешер; хакас. чазар) [16. С. 134].

Представления, связанные с почитанием молодой березки, существуют почти у всех тюркоязычных народов Сибири. Отражение языческого почитания березы рассматривается и в существовании специального праздника березы чачил у алтайских народов [17. С. 54].

У якутов существуют представления о том, что на месте захоронения человека вырастает березка (хахыйах) как воплощение человеческой души. Такому представлению сопутствует древний обычай, когда втыкали срезанную молодую березку в берестяное покрытие гроба [18. С. 43]. По якутским поверьям, березовые ветки воспринимались как некий мост, соединяющий человекаайыы с небесными божествами. Зеленые ветки березы у многих народов выступают в качестве необходимого атрибута многих церемоний и служат символом умершего предка. По мнению Е.Н. Романовой, БІсыах был связан когда-то с погребально-поминальной обрядностью. Так, якутский обряд Айах тутуу (Поминовения богов и святых предков), совершаемый внутри Могол ypacbl, служит своеобразным подтверждением данной гипотезы [11. С. 144].

Особого внимания при этом заслуживает использование березы и его частей в качестве ритуального предмета. Так, по археологическим и фольклорным материалам известно, что в старину, когда человек умирал, его накрывали расшитыми узорами берестяными полотнами, «такими же, какие шли на постройку берестяной урасы» [19. С. 24]. Существует предположение, что на гроб укладывали именно часть берестяной покрышки урасы. Так, береста (береза) имела свойство способствовать перерождению человеческой души ${ }^{1}$.

По архивным сведениям, внутри Могол урасы могли совершать обряд отправления души старого человека к предкам. Во время этого обряда распитие кумыса совершалось против хода солнца.

Считалось, что после этого старики, участвовавшие в данном ритуале, могли спокойно отправиться в мир предков. Согласно якутским преданиям, ритуальное кумысопитие в честь святых предков стало последним угощением Омогой бая (первопредок якутского народа), которого тут же, внутри урасы похоронили [20. C. 231].

В связи с этим следует отметить, что в древности могильную яму называли моголо, монголо. По мнению В.Е. Васильева, данный термин может быть семантически связан с Могол урасой [18. С. 47], ставшей своеобразным склепом для душ предков.

Таким образом, Могол ураса - символ, в котором перекликаются архаические представления и воззрения древних предков саха: культ матери-богини (Земли), отраженные в глубинной семантической структуре. Как культовое сооружение Могол ураса связана с культом предков и идеей перерождения, перевоплощения души человека. 
В этом контексте следует рассмотреть и символическое окружение ритуальных урас, сооружаемых во время различных обрядов.

У якутов, когда женится молодой человек, говорят: дьиэлэммит (букв.: «обзавелся домом»), имея в виду, что тот привел в дом молодую жену. Интересно, что когда девушка выходит замуж, про нее не говорят дbuэлэммит. Но зато перед отправлением свадебного поезда невесты в дом жениха ее благословляют следующим образом: «Алаһа дьиэни тэринэ, аал уоту оттуна, алтан сэргэни туруоруна, аттанар кэмин дьэ кэллэ» («Пришел твой час, построить уютный дом, разжечь пламенный огонь, установить медную коновязь») [21. С 53-54]. Так, в старину Могол урасу в разборном виде привозила с собой невеста (остов урасы изготовлялся мужчинами-родственниками, а берестяные полотна начинали заготовляться почти сразу после рождения дочери - матерью. - Н.Д.), которая являлась основным компонентом приданого богатой невесты. Обычай готовить жилище стороной невесты распространен у многих тюрко-монгольских народов. Народная традиция запечатлена также и в поговорке народов Северной Азии: «Иметь юрту, иметь жену». Данный обычай, по мнению исследователей, отражает следы былой матрилокальности брака [22. С. 55].

Примечательно, что в языке сновидений и символических текстах - загадках, ураса задается через женский образ: Могол дьахтар юс курдаax yhy (Говорят, почтенная женщина имеет три опояски); Уhyктаax тебелеех дьахтар оройунан тыlblнар yhy (Говорят, остроголовая женщина дышит макушкой) [10. С. 23-24]; Хотун дьахтар хонуу ортотугар хоройон турар yhy (Есть, говорят, важная госпожа, стоящая посередине луга) [23. С. 34, 47].

Параллелизм женского образа с урасой более всего запечатлен в знаковом оформлении свадебной одежды невесты. Так, старинный свадебный головной убор невесты Ураһа бэгэһэ (Шапка ураса) представлял собой высокую конусообразную шапку из бересты.

Интересно то, что о наличии в костюмном ансамбле якутской невесты Шапки ураса известно только по фольклорным материалам, существование этого примечательного головного убора не подтверждено археологическими находками. Это можно объяснить тем, что Шапка ураса была связана только с культом aйblbl, а потому не могла стать погребальной одеждой женщины, и одевалась только раз - во время свадебного ритуала - своеобразного причащения к космической структуре нового жизненного пространства.

В якутских алгысах-благопожеланиях, адресованных главным образом невесте, довольно часто употребляется выражение аал уоту отто, aлаһa дьиэни тэринэ (досл. «разведи священный огонь, обзаведись жилищем алаһa»). В якутском языке термин алаһа является одним из эпитетов, означающих жилище - дьиэ якутов. Термин алаһа является производным от древнетюркского слова алачу - жилище [24. С. 60].
Так, например, подобные виды жилища, причем связанные исключительно со свадебной обрядностью, существовали у многих тюркоязычных народов: аланчык, алажи уг, алачык [17. С. 125].

Генетическая связь термина алаһа с названиями свадебных переносных жилищ тюркоязычных народов позволяет предположить, что алаһa - название ритуальной урасы невесты, которая в силу каких-то причин исчезла из употребления. Возможно, берестяная занавеска комнатки девушки xannaxчы caбыbыma впоследствии переняла все ритуальные функции урасы невесты [24. C. 41].

Сразу после приезда невесты в дом родителей мужа ее помещали за ритуальную занавеску хапnахчьl. Во время свадебного пиршества (на протяжении всего времени) невеста находилась за занавеской во всем своем праздничном одеянии. Только по истечении трех дней заканчивалась ритуальная «изоляция» невесты. С нее снимали свадебный наряд, переодевали в домашнюю одежду - из комнатки невеста выходила в качестве замужней женщины. Так, в символическом плане берестяной занавес хапnaxчbl выступал как материнская утроба, внутри которой невеста перерождалась из одного качественного состояния в другое [25. С. 28]. Неслучайно в загадках ураса символизирует материнскую утробу: Биир сиргэ ураһа иһигэр чыblчаах огото сытар $y h y$ (Говорят, на одном месте стоит ураса, внутри которой находится птенец) [26. С. 34].

Семантическая связь берестяной урасы с моделированием новой жизни прослеживается в обряде Aüblblcblm amaapblbl (обряд проводов богини Айыысыт), отправляемом на третий день после рождения ребенка.

Сначала тщательно готовили атрибуты, используемые во время обряда: вырезали из дерева маленький лучок и стрелу, а из бересты - фигурки животных и изображение солнца и луны. Недалеко от места, где находилась роженица, вырывали в земле небольшую ямку, устилали дно белым волосом из конской гривы и поверх него помещали небольшой берестяной турсучок с последом, накрытый кусочком бересты, саму ямку засыпали землей, но не доверху. Вырезали жердочки для остова урасы и втыкали в землю вокруг ямки с последом. Затем, изготовив миниатюрную урасу, на южной стороне втыкали шест с привязанным к нему веревкой берестяным кружком, изображавшим солнце, на северной стороне устанавливали такой же шест с изображением луны.

Если новорожденным был мальчик, то к стенке урасы, с южной ее стороны, прислоняли берестяную фигуру лося головой на восток; за нею помещали лыжи, а перед лосем - фигуру собаки. Если девочка - фигуру ножницы. Когда все было готово, поджигали щепочки, лежавшие в ямке, в центре урасы, от чего она загоралась. Если новорожденный был мальчиком, то мать, взяв лучок и стрелу, стреляла в фигурку лося, которая падала в пылающий костер, если девочка - изображе- 
ния животных присутствовавшие брали не руками, а захватывали ножницами [27. С. 84-85].

В данном обряде сжигание модели урасы над зарытым последом является выпусканием деторождающей силы последа и передачей ее функций на весь дом [28. С. 25].

«Перерождающее» свойство урасы наглядно показано и в следующем промысловом обряде. Охотник, добывший лисицу (рысь), обязательно сооружал над ней коническое сооружение, напоминающее урасу. Затем, осторожно взяв лису оттуда, возвращался домой. Лисицу, как лесную гостью, надо было вносить в дом не через дверь, а через окно. Перед этим охотник надевал на лису женскую шапку дьабака, украшал ее серебряными украшениями. Домашние, взяв лисицу, сразу смазывали ее ноздри маслом или сливками, т.е. «угощали» божественной пищей. Остаток жертвы для задобрения духа-хозяина очага охотник выливал в огонь [29. С. 96]. Завернутую в женскую шубу лисицу (или рысь) укладывали на женское ложе. Только по истечении трех дней можно было снять шкуру.

Имитативные действия охотника с рысью и лисой в промысловых обрядах повторяют ритуальные действия свадебного обряда. Таким образом, в вышеуказанном обряде разыгрывается символическая «свадьба» охотника с самой хозяйкой леса (женской ипостасью божества охоты).

Совершение символического захоронения лисицы внутри шалаша, а также помещение невесты внутри урасы (внутри xannaxчb) может быть связано и с культом умирающего и воскресающего зверя. Внутри «берестяной оболочки» невеста «умирает» / «возвращается в инобытие» и находится в ритуальной «изоляции» три дня, затем возрождается в качественно другом состоянии - жены, будущей матери. Так и лиса: после физической смерти внутри человеческого сооружения возвращается из мира природы в образе матери-зверя.

Итак, как ритуальный символ Могол ураса воплощает собой своеобразный культовый храм, связанный с архаическими верованиями: культом матери-земли, впоследствии культом предков. В этом контексте как особый ритуальный предмет выделяется береста - заключившая в свою семантическую нагрузку медиативную, продуцирующую и апотропеическую функции, т.е. как некая оболочка, способствующая перерождению душикут неофита и его перевоплощению.

\title{
ПРИМЕЧАНИЕ
}

\begin{abstract}
${ }^{1}$ Так, по воткнутой в крышке гроба березке, как по вертикальной оси, душа человека улетает наверх. Поэтому древние якуты верили в то, что душа человека превращается в растительность, и говорили: «Кэлэр кэнчээри ыччатыл»» (букв.: «будущая молодая поросль»). Также существовали мифологические представления, согласно которым душа-кут человека обитала на деревьях. У шаманов их душа-кут воспитывается на дереве Ыйык мас, от расположения которых зависит их шаманская сила. Считалось, чем выше уровень на дереве, тем сильнее шаманская сила. Интересно то, что когда наступал срок «рассекания» тела будущего шамана, на месте, которое знал только сам посвящаемый, в лесу, в глухой местности строили урасу. Эту урасу должны были строить или саман шаман, или молодые, еще не женившиеся парни. Таким образом, внутри урасы происходило своеобразное перерождение шамана.
\end{abstract}

\section{ЛИТЕРАТУРА}

1. Гоголев А.И. Историческая этнография якутов. Якутск : Изд-во ЯГУ, 1986

2. Оразов А., Чарыев Д. Некоторые верования и обряды туркмен, связанные с юртой (XIX - начало ХX в.) // Кочевое жилище народов Средней Азии и Казахстана. М., 2000.

3. Алексеев Р.П. Ураһалар // Архив Якутского научного центра Сибирского отделения Российской академии наук (далее - Архив ЯНЦ СО РАН). Ф. 5. Оп. 6. Д. 98. Л. 24-32.

4. Ионова О.В. Жилые и хозяйственные постройки якутов (историко-этнографический очерк). 1951 г. // Архив ЯНЦ СО РАН. Ф. 5. Оп. 1. Д. 224. Л. 1-351.

5. Жамбалова С.Г. Поселения и жилища // Буряты. Серия «Народы и культуры». М. : Наука, 2004. С. 136-151.

6. Саввин А.А. Этнографические записи и заметки. 1938-1941 гг. // Архив ЯНЦ СО РАН. Ф. 4. Оп. 12. Д. 6. Л. 1-56.

7. Ионова О.В. Жилые и хозяйственные постройки якутов // Сибирский этнографический сборник. М. ; Л., 1952. Т. 1. С. 239-319.

8. Жамбалова С.Г. Традиционная охота бурят. Новосибирск : Наука, 1991.

9. Зыков Ф.М. Поселения, жилища и хозяйственные постройки якутов ХІХ - начала ХХ в. : историко-этнографическое исследование. Новосибирск : Наука, 1986

10. Ксенофонтов Г.В. Материалы об Ысыахе // Архив ЯНЦ СО РАН. Ф. 4. Оп. 1. Д. 12 а/б. Л. 1-189.

11. Романова Е.Н. Якутский праздник Ысыах. Истоки и представления. Новосибирск : Наука, 1994.

12. Львова Э.Л., Октябрьская И.В., А.М. Сагалаев, М.С. Усманова. Традиционное мировоззрение тюрков Южной Сибири. Пространство и время. Вещный мир. Новосибирск : Наука, 1988.

13. Неустроев Б.Ф.-Мандар. Саха туоһа (Якутская береста). Якутск : Бичик, 1996 (на якут. яз.).

14. Эргис Г.У. Очерки по якутскому фольклору. М. : Наука, 1974.

15. Дьяконова Е.Н. Символика в якутском обряде «ысыах» // Проблемы изучения традиций в культуре народов мира. М., 1990. Вып. 1. С. 4857.

16. Антонов Н.К. Материалы по исторической лексике якутского языка. Якутск : Кн. изд-во, 1971.

17. Дьяконова В.П. Алтайцы (материалы по этнографии теленгитов Горного Алтая. Горноалтайск : Юч-Сюмер, 2001.

18. Васильев В.Е. Саха терут итэгэлэ былыргы сэһэннэргэ (Якутское традиционное верование в преданиях). Якутск : Бичик, 2006 (на якут. яз.).

19. Константинов И.В. Материальная культура якутов XVIII века. Якутск : Кн. изд-во, 1971.

20. Боло С.И. Прошлое якутов до прихода русских на Лену : (По преданиям якутов бывшего Якутского округа). Якутск : Бичик, 1994 (на якут. яз.).

21. Сивцева В., Баишева А. Дьиэ малааһына (Новоселье). Якутск : Бичик, 2005 (на якут. яз.).

22. Содномпилова М.М. Семантика жилища в традиционной культуре бурят. Иркутск, 2005.

23. Попов А.А. Старинная якутская берестяная юрта // Сборник Музея антропологии и этнографии. Л., 1949. Т. 10.

24. Слепцов П.А. Традиционная семья и обрядность у якутов. ХІХ - начало XX в. Якутск : Кн. изд-во, 1989. 
25. Васильева Н.К. Знаковые функции одежды в мифоритуальной традиции народа саха // Гуманитарная наука в трудах молодых исследователей. Якутск : ИГИ АН РС (Я), 2005. С. 21-37.

26. Саввин А.А. Материалы Вилюйского улуса // Архив ЯНЦ СО РАН. Ф. 4. Оп. 12. Д. 33. Л. 1-67.

27. Иванов С.В. Старинный якутский обряд, связанный с рождением ребенка // Сборник Музея антропологии и этнографии. Л., 1971. Т. 27.

28. Романова Е.Н., Слепцов П.А., Колодезников С.К. Жизненный круг у якутов // Илин. 1992. № 1. С. 36-40.

29. Алексеев Н.А. Ранние формы религии тюрко-язычных народов Сибири. Новосибирск : Наука, 1980.

Danilova Nataliya K. Institute of the Humanities and the indigenous peoples of the Siberian Branch of the Russian academy of sciences (Yakutsk, Russia). E-mail: Tachika@ mail.ru

\section{SACRAL SPACE: ARCHITECTURAL EMBODIMENT OF TRADITIONAL OUTLOOK.}

Keywords: Sakha people; model of the world; outlook; Mogol Urasa; semantics and image; the myth and ritual; cultural tradition; sacred space.

The Mogol Urasa - monumental fixed structure of the Sakha people, covered with birch-bark paintings. The housing settlement complexes Mogol Urasa was a kind of summer homes. It acted as a measure of nobility and wealth of man. In the semantic context Mogol Urasa was associated with a model of the universe, with the iconic architecture that has remained conscious ideological program of symbolic simulation of the universe. Analysis of folklore and ethnographic materials revealed that birch bark Urasa as the home - the keeper of life was associated with the cult of the mother goddess (the cult of the earth) and ancestor worship. The cultural heritage of the Sakha people is a key symbol of the sacred space. Sakha people is the northernmost Turkic peoples of Siberia, in the ethnogenesis of which various Turkic-Mongol tribes and autochthonous attended. The uniqueness of this people is that they are an island of south culture of Turkic-speaking ancestors in the space of the Arctic civilization. One of the key symbols of the culture of the Sakha people, has incorporated into its semantic, functional and structural space tradition of nomadism, is a Mogul - Uras - saving stationary housing, covered with birch-bark. Mogul Uras is riding architectural taste, absorbed all the richness of people's knowledge and understanding. It is no accident it is called Us kurduulaah Mogul Uras 'With three bowls Mogul Uras'. The Yakut people as a result of a complex of ethno - and cultural genesis created the unique architectural culture with southern elements in the Far North. Researchers differently explain the origin of this type of housing. Some thought that the lack of housing with the construction as in Mogul Uras at the Turko-Mongol peoples suggests that it arose as a result of sedentary farming, instead of the transfer of light portable conical dwellings taken over from indigenous peoples (Tungus). Others argued that Mogul Uras had its prototypes in the south, then to the extent of adaptation to the new climatic conditions in the North there was a change, part complexity and improve its structure. Data on language picture of the world, the symbolic content and design features indicate that the Mogul Uras was possible roots of the palace buildings of nomadic tribes. So, Uras Mogul could build only head of the clan, as it performed a measure of nobility and wealth. Having examined the complex semantic loading Mogul Uras ritual space and cultural linguistic analysis of the term "Mogul", we come to the conclusion that the birchbark Uras as the home - the keeper of human life, was associated with the cult of the mother goddess (the cult of the earth) and ancestor worship. In this context, as a special ritual object is allocated elm - concluded in its semantic load of mediation, produced and apotropaic functions, ie as a kind of envelope, promoting regeneration of the soul-kut neophyte and his reincarnation. Thus, the use of Mogul Uras rites of the life cycle, connects it with the idea of rebirth and reincarnation.

\section{REFERENCES}

1. Gogolev, A.I. (1986) Istoricheskaya etnografiya yakutov [Historical ethnography of Yakuts]. Yakutsk: Yakutsk State University.

2. Orazov, A. \& Charyev, D. (2000) Nekotorye verovaniya i obryady turkmen, svyazannye s yurtoy (XIX - nachalo XX v.) [Some beliefs and practices of the Turkmen related to the yurt (the 19th - early 20th centuries)]. In: Vasilieva, G.P. (ed.) Kochevoe zhilishche narodov Sredney Azii i Kazakhsta$n a$ [Nomadic dwelling of Central Asian and Kazakhstan peoples]. Moscow: Nauka.

3. Alekseev, R.P. (n.d.) Urahalar. Archive of the Yakut Scientific Center of the Siberian Branch of the Russian Academy of Sciences (YaSC SB RAS). Fund 5. List 6. File 98.

4. Ionova, O.V. (1951) Zhilye i khozyaystvennye postroyki yakutov (istoriko-etnograficheskiy ocherk) [Residential and farm buildings of Yakuts (a historical and ethnographic essay)]. Archive of the Yakut Scientific Center of the Siberian Branch of the Russian Academy of Sciences (YaSC SB RAS). Fund 5. List 1. File 224.

5. Zhambalova, S.G. (2004) Poseleniya i zhilishcha [Settlements and dwellings]. In: Abaeva, L.L. \& Zhukovskaya, N.L. (eds) Buryaty [Buryats]. Moscow: Nauka. pp. 136-151.

6. Savvin, A.A. (1938-1941) Etnograficheskie zapisi i zametki. 1938-1941 gg. [Ethnographic records and notes. 1938-1941]. Archive of the Yakut Scientific Center of the Siberian Branch of the Russian Academy of Sciences (YaSC SB RAS). Fund 4. List 12. File 6.

7. Ionova, O.V. (1952) Zhilye i khozyaystvennye postroyki yakutov [Residential and farm buildings]. In: Sibirskiy etnograficheskiy sbornik [Siberian Ethnographic collection]. Moscow; Leningrad: Nauka. pp. 239-319.

8. Zhambalova, S.G. (1991) Traditsionnaya okhota buryat [Traditional hunting of Buryats]. Novosibirsk: Nauka.

9. Zykov, F.M. (1986) Poseleniya, zhilishcha i khozyaystvennye postroyki yakutov XIX - nachala XX v.: istoriko-etnograficheskoe issledovanie [The settlements, dwellings and outbuildings of Yakuts in the nineteenth - early twentieth centuries]. Novosibirsk: Nauka.

10. Ksenofontov, G.V. (n.d.) Materialy ob Ysyakhe [Materials about Ysyakh]. Archive of the Yakut Scientific Center of the Siberian Branch of the Russian Academy of Sciences (YaSC SB RAS). Fund 4. List 1. File $12 \mathrm{a} / \mathrm{b}$.

11. Romanova, E.N. (1994) Yakutskiy prazdnik Ysyakh. Istoki i predstavleniya [A Yakut holiday Ysyakh. Origins and presentation]. Novosibirsk: Nauka.

12. L'vova, E.L., Oktyabr'skaya, I.V., Sagalaev, A.M. \& Usmanova, M.S. (1988) Traditsionnoe mirovozzrenie tyurkov Yuzhnoy Sibiri. Prostranstvo i vremya. Veshchnyy mir [The traditional worldview of the Turks of southern Siberia. Space and time. Material world]. Novosibirsk: Nauka.

13. Neustroev, B.F. (1996) Sakha tuoha [The Yakutia birchbark]. Yakutsk: Bichik. (In Yakut).

14. Ergis, G.U. (1974) Ocherki po yakutskomu fol'kloru [Essays on the Yakut folklore]. Moscow: Nauka.

15. D'yakonova, E.N. (1990) Simvolika v yakutskom obryade "ysyakh" [The symbolism of the rite in the Yakut "Ysyakh"]. In: Brusina, O.I. \& Daragan, N.Ya. (eds) Problemy izucheniya traditsiy v kul'ture narodov mira [The study of traditions in the culture of the peoples of the world]. Moscow: USSR AS. pp. 48-57.

16. Antonov, N.K. (1971) Materialy po istoricheskoy leksike yakutskogo yazyka [Materials on the history of the Yakut language vocabulary]. Yakutsk: Book Publ.

17. D'yakonova, V.P. (2001) Altaytsy (materialy po etnografii telengitov Gornogo Altaya [Altai (Ethnographic materials about Telengits of the Altai Mountains]. Gornoaltaysk: Yuch-Syumer.

18. Vasil'ev, V.E. (2006) Sakha terut itegele bylyrgy sehennerge [Yakut traditional belief in legends]. Yakutsk: Bichik.

19. Konstantinov, I.V. [1971] Material'naya kul'tura yakutov XVIII veka [The material culture of Yakuts of the 18th century]. Yakutsk: Book Publ. 
20. Bolo, S.I. (1994) Proshloe yakutov do prikhoda russkikh na Lenu: (Po predaniyam yakutov byvshego Yakutskogo okruga) [Past of the Yakuts before the arrival of Russian to the Lena: (According to the Yakut legends)]. Yakutsk: Bichik.

21. Sivtseva, V. \& Baisheva, A. (2005) D'ie malaahyna [Housewarming]. Yakutsk: Bichik.

22. Sodnompilova, M.M. (2005) Semantika zhilishcha v traditsionnoy kul'ture buryat [Semantics of the dwelling in Buryat traditional culture]. Irkutsk: SB RAS.

23. Popov, A.A. (1949) Starinnaya yakutskaya berestyanaya yurta [Old Yakut birch bark yurts]. In: Tolstov, S.P. (ed.) Sbornik Muzeya antropologii $i$ etnografii [Collection of the Museum of Anthropology and Ethnography]. Leningrad: USSR AS.

24. Sleptsov, P.A. (1989) Traditsionnaya sem'ya i obryadnost' u yakutov. XIX - nachalo XX v. [The traditional family and rituals of Yakuts in the 19th early 20th centuries]. Yakutsk: Book Publ.

25. Vasil'eva, N.K. (2005) Znakovye funktsii odezhdy v miforitual'noy traditsii naroda sakha [Marker functions of clothes in mythos-ritual traditions of the Saha people]. In: Alekseeva, A.A. (ed.) Gumanitarnaya nauka $v$ trudakh molodykh issledovateley [Humanities in the works of young researchers]. Yakutsk: RF Academy of Sciences. pp. 21-37.

26. Savvin, A.A. (n.d.) Materialy Vilyuyskogo ulusa [Materials of Vilyuysky District]. Archive of the Yakut Scientific Center of the Siberian Branch of the Russian Academy of Sciences (YaSC SB RAS). Fund 4. List 12. File 33.

27. Ivanov, S.V. (1971) Starinnyy yakutskiy obryad, svyazannyy s rozhdeniem rebenka [The old Yakut ritual associated with the birth of the child]. In: Tolstov, S.P. (ed.) Sbornik Muzeya antropologii i etnografii [Collection of the Museum of Anthropology and Ethnography]. Leningrad: USSR AS.

28. Romanova, E.N. Sleptsov, P.A. \& Kolodeznikov, S.K. (1992) Zhiznennyy krug u yakutov [The life circle of Yakuts]. Ilin. 1. pp. 36-40.

29. Alekseev, N.A. (1980) Rannie formy religii tyurko-yazychnykh narodov Sibiri [Early forms of religion of Turkic peoples in Siberia]. Novosibirsk: Nauka. 